\title{
Wilson's disease and hepatocellular carcinoma: possible protective role of copper
}

\author{
M L WILKINSON, B PORTMANN, AND ROGER WILLIAMS \\ From The Liver Unit, King's College Hospital and Medical School, Denmark Hill, London
}

SUMMARY A male patient with Wilson's disease developed a hepatocellular carcinoma after treatment for nine years with D-penicillamine. Examination at necropsy showed that excess liver copper had been effectively removed. As copper has been shown to protect against chemically induced hepatocellular carcinoma in rats, this may be the reason for the extreme rarity of hepatocellular carcinoma in patients with Wilson's disease and possibly in other liver diseases with hepatic copper overload.

Hepatocellular carcinoma is a common complication of longstanding cirrhosis and, overall, the likelihood of this in any particular aetiological group of patients has been said to depend on the proportion of men within that group and the duration of cirrhosis. At one end of the spectrum are patients with haemochromatosis or $\mathrm{HBsAg}$ positive cirrhosis who are predominantly male and at the other end are those with primary biliary cirrhosis or $\mathrm{HBsAg}$ negative chronic active hepatitis with very few men affected. ${ }^{1}$ It is therefore suprising that in Wilson's disease (hepatolenticular degeneration) which has an even sex incidence and a substantial proportion of patients surviving for long periods, there have only been two proven cases and one possible further instance..$^{2-4}$ In this paper we describe a fourth case and discuss the relationship between the development of hepatocellular carcinoma and the protective role of copper overload which has been shown experimentally.

\section{Case history}

A 31 year old male chemical engineer was referred to the Liver Unit in December 1971 after an episode of melaena. There had been previous episodes in 1968 and 1969 . He had recently noticed mental fuzziness and difficulty in concentrating at work and on examination Kayser-Fleischer rings and hepato-

Received for publication 14 October 1982 splenomegaly were present. Investigations showed a serum bilirubin concentration of $10.3 \mu \mathrm{mol} / 1(0.6$ $\mathrm{mg} / \mathrm{dl}$ ); aspartate aminotransferase $34 \mathrm{IU}$ (normal $<50$ IU); alkaline phosphatase 55 IU (normal $<100$ IU); albumin $30 \mathrm{~g} / \mathrm{l}$; total protein $53 \mathrm{~g} / \mathrm{l}$; and prothrombin time 17 seconds (control 12 seconds). Immunoglobulins, autoantibodies, $\mathrm{HBsAg}$, and alphafetoprotein were normal or negative.

Hepatic arteriogram and splenic venogram showed gastric and oesophageal varices with patent splenic and portal veins. Electroencephalogram was normal.

The diagnosis of Wilson's disease was confirmed by the finding of a zero serum caeruloplasmin concentration on two occasions, a low serum copper concentration of $0.8 \mu \mathrm{mol} / 1(5 \mu \mathrm{g} / \mathrm{dl})$ and $1.3 \mu \mathrm{mol} / 1$ $(8.1 \mu \mathrm{g} / \mathrm{dl})$. Urinary copper was $0.94 \mu \mathrm{mol}(58.9 \mu \mathrm{g})$ and $1.15 \mu \mathrm{mol}(72 \mu \mathrm{g})$ per 24 hours (normal $<0.8$ $\mu \mathrm{mol}(50 \mu \mathrm{g}) / 24 \mathrm{~h})$ before and $6.65 \mu \mathrm{mol}(410 \mu \mathrm{g})$ per 24 hours after D-penicillamine. Investigations of the family revealed a low caeruloplasmin and raised urinary copper excretion in his sister (who was subsequently treated with D-penicillamine) with normal concentrations in both parents.

In January 1972 a lienorenal anastomosis was performed and he was started on D-penicillamine therapy. This was continued for the next nine and a half years at dosages ranging from 725 to $900 \mathrm{mg}$ daily (Fig. 1). In 1973 he had a minor episode of encephalopathy and in 1980 he developed fluid retention which was thereafter controlled by spironolactone. He was otherwise well and in full time 


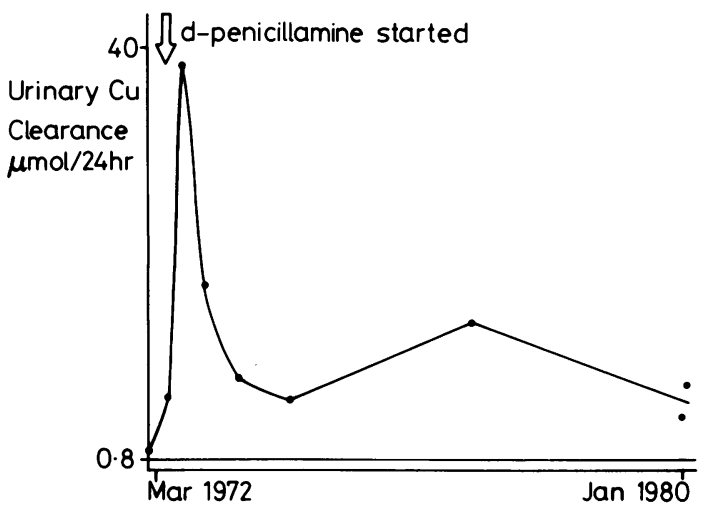

Fig. 1 Pattern of urinary 24 hour copper excretion over eight years from diagnosis up to 18 months before death. 0.8 $\mu \mathrm{mol} / 24 \mathrm{~h}$ is the upper limit of normal.

employment until his final illness. This began with melaena from oesophageal varices in June 1981 and in August he was admitted to another hospital after a massive haematemesis. The following day he lapsed into coma and received artificial ventilation for the next two weeks. He had a further haemorrhage after which he had focal fits, and he was transferred to King's College Hospital in September 1981.

On examination he was in grade II encephalopathy. The liver was palpable $2 \mathrm{~cm}$ below the costal margin and there were signs of bilateral patchy chest consolidation but no focal neurological signs. Investigations showed little change in liver function tests compared with June 1981 except for serum bilirubin which had risen to $162 \mu \mathrm{mol} / \mathrm{l}$. All markers for hepatitis B virus were negative by radioimmunoassay. There was initially some improvement in conscious level; however, he had further convulsions, bronchopneumonia, and an iliofemoral thrombosis developed, and finally his level of coma deepened. He died on 15 October 1981.

\section{HISTOLOGY OF LIVER}

The first percutaneous liver biopsy taken preoperatively in 1971 (Fig. 2) showed a well established cirrhosis with prominent cellular and nuclear pleomorphism including ballooned cells and frequent nuclear vacuolations with peripheral microvesicular transformation of the cytoplasm. In places there were larger foci of fatty vacuolation and of iron deposition. There was some non-specific inflammation, mostly confined to the fibrous areas, with only patchy disruption of the limiting plate. Orcein staining revealed finely divided granules of copper-associated protein in large groups of cells patchily and randomly distributed. The wedge biopsy specimen showed the same features and confirmed the presence of micronodular cirrhosis.

Follow up biopsy showed a more collapsed liver with broader bands of inflamed connective tissue surrounding small hyperplastic nodules. Perls' stain revealed grade I siderosis with an irregular distribution. Orcein staining was negative.

At necropsy the lienorenal shunt was patent and the inferior vena cava was normal. There were dilated tortuous veins in the lower oesophagus but no blood within the gastrointestinal tract. The surface of the liver showed micronodular cirrhosis. It weighed $1502 \mathrm{~g}$ and on sectioning there were large haemorrhagic nodules up to $5 \mathrm{~cm}$ in diameter (Fig. $3)$. There was no evidence of tumour in any other organ. Histological examination showed nodules composed of a well-differentiated hepatocellular carcinoma of trabecular pattern with evidence of bile formation (Fig. 4). On orcein staining of the surrounding liver in contrast to the initial biopsy but similar to the one taken one year before death, very few cells or groups of cells contained copper-binding protein, usually those cells enmeshed in fibrous tissue. Liver copper level was $48 \mathrm{mg} / 100 \mathrm{~g}$ dry weight (normal $<50 \mathrm{mg} / 100 \mathrm{~g}$ ) as determined by flame photometry at the National Hospital for Nervous Diseases, Queen Square, London.

\section{Discussion}

One possible explanation for the low incidence of hepatocellular carcinoma in patients with Wilson's disease is that the presence of copper in the hepatocytes protects them from the oncogenic consequences of cirrhosis. There have been several reports showing protection by increased dietary copper from chemically included hepatic carcinogenesis in rats. ${ }^{5-8}$ If this mechanism operates in Wilson's disease protection could be reversed once the excess copper has been removed by treatment but the time needed to remove excess copper by chelation therapy is not accurately known. Sherlock $^{9}$ stated that complete decoppering is unusual even after many years of treatment and according to Walshe ${ }^{10}$ the speed of decoppering depends on the dose of penicillamine, many patients managing on $900 \mathrm{mg} /$ day but some requiring 2-3 g/day to remain in negative copper balance. Another factor is dietary intake which is usually from $2-5 \mathrm{mg} /$ day but with water supplied in copper pipes, shellfish, nuts, chocolate, and some other foods this figure may be much higher. The only certain indication that 'decoppering' is adequate is a repeat chemical estimation of copper in liver tissue. 


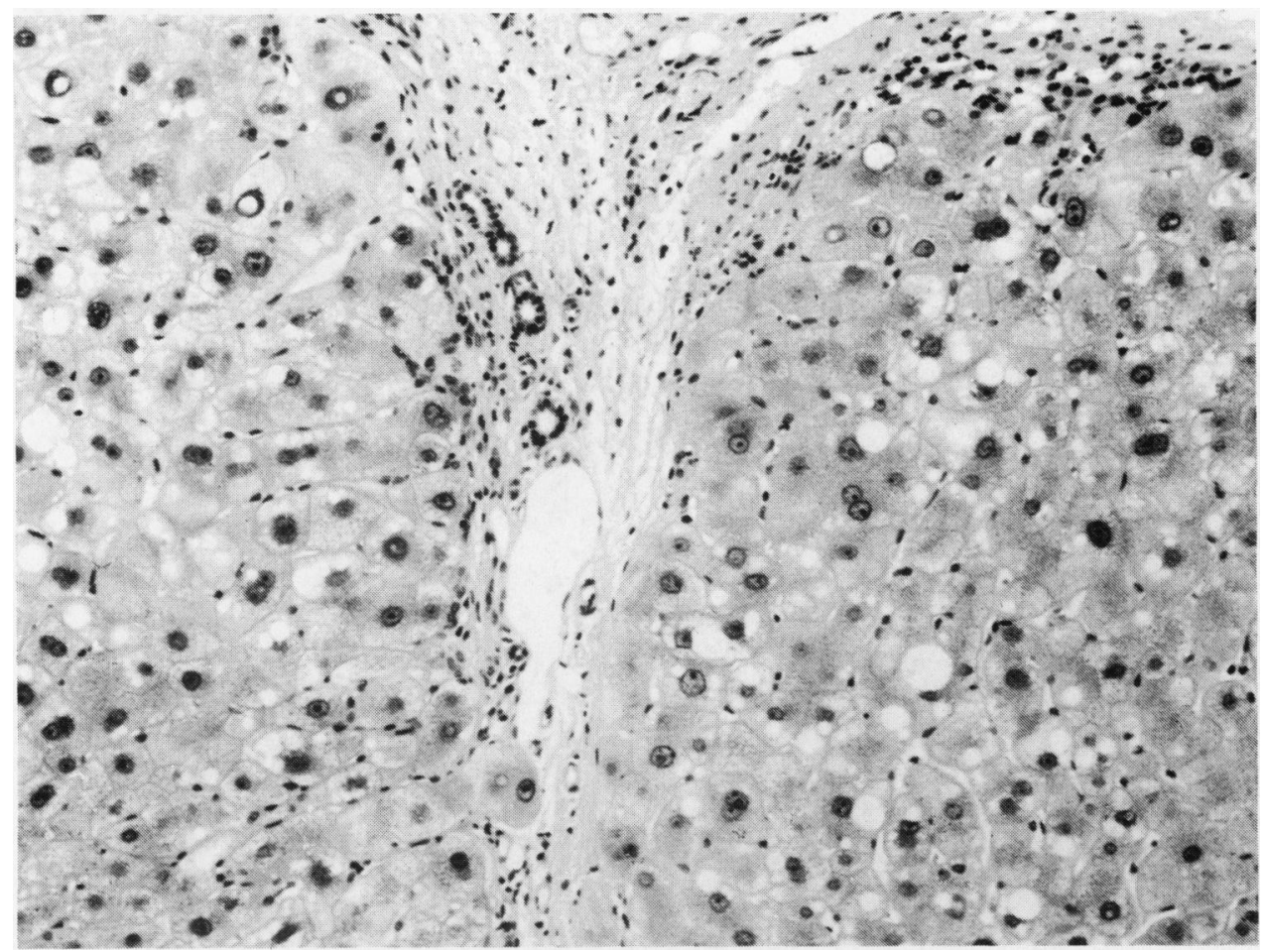

Fig. $2 H \& E$ stained section of percutaneous liver biopsy in 1972 showing prominent fibrous septum, cellular and nuclear pleomorphism, ballooned cells with frequent nuclear vacuolation, and peripheral cytoplasmic microvesicular transformation. Mild patchy inflammation is seen disrupting the limiting plate $(H \& E \times 300)$.

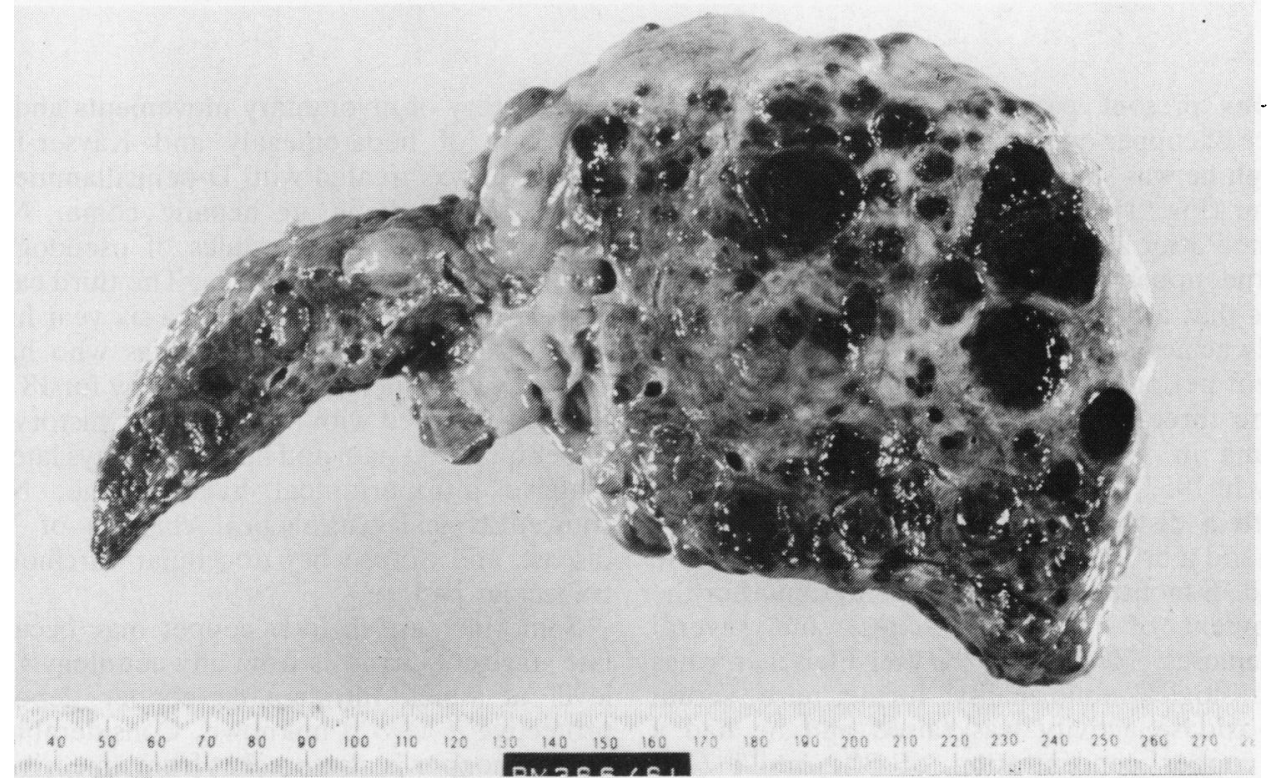

Fig. 3 Cut surface of the liver at necropsy showing multiple haemorrhagic tumour nodules. 


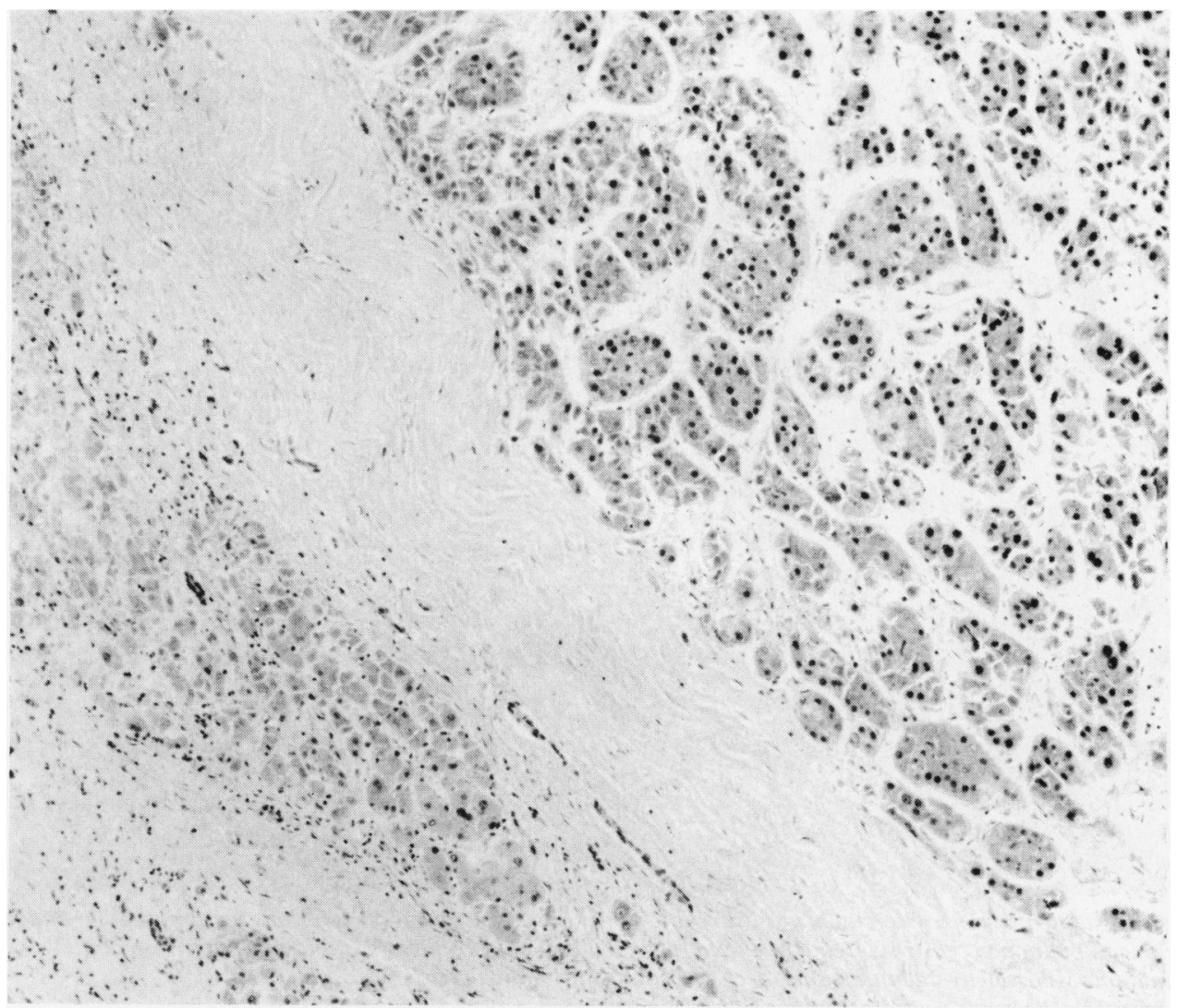

Fig. 4 Sections of the tumour showing well differentiated hepatocellular carcinoma of trabecular pattern $(H \& E \times 130)$.

Thus our present patient had no histochemical evidence of copper overload 21 months before death (although he was still excreting over $5 \mu \mathrm{mol} / 24 \mathrm{~h}$ in his urine (Fig. 1)) and a tissue copper estimation performed after death showed the concentration to be at the upper end of the normal range. This suggests that a normal tissue copper concentration was only achieved towards the end of the nine year treatment period.

Of the three previous reports of hepatocellular carcinoma in Wilson's disease ${ }^{2-4}$ the first, from Norway in $1957,{ }^{2}$ is the least certain. A 14 year old boy with a distant cousin who had had Wilson's disease and a brother with possible Wilson's disease had died 18 months after first presentation after the development of jaundice, ascites, and several haematemeses. He had no Kayser-Fleischer rings nor neurological abnormality; furthermore, serum copper-oxidase activity was raised and he had a serum copper concentration of $30 \mu \mathrm{mol} / \mathrm{l}$ (199 $\mu \mathrm{g} / 100 \mathrm{ml})$. The second was a Frenchman with a 41 year history of involuntary movements and at least 22 years of hepatomegaly and Kayser-Fleischer rings. He was treated with D-penicillamine for five years before dying in hepatic coma. Necropsy showed cirrhosis and nodules of pseudoglandular type hepatocellular carcinoma. The third case was a 32 year old Japanese man with a six year history of tremor and Kayser-Fleischer rings who had been treated with D-penicillamine therapy for 18 months. He was admitted with a two-months history of right upper quadrant pain and he died 12 days later after a massive intraperitoneal haemorrhage. Necropsy showed typical pathological changes of Wilson's disease and diffuse hepatocellular carcinoma of a trabecular pattern.

Some increase in liver copper may occur in the late stages of cirrhosis from any aetiology ${ }^{11}$ and the level at which intrahepatic copper deposits are protective in vivo is unknown. Considerable excess hepatic copper is also present from an early stage in certain chronic cholestatic conditions, especially 
primary biliary cirrhosis in which hepatocellular carcinoma has been reported only rarely. ${ }^{12}$ As it is predominantly a disease of women this also has to be taken into account. The latter does not apply, however, to primary sclerosing cholangitis ${ }^{13} 14$ in which we have been unable to find any reports of associated hepatocellular carcinoma and such considerations may have added relevance now that penicillamine is being used in the treatment of these patients as well as in primary biliary cirrhosis.

\section{References}

1 Johnson PJ, Krasner N, Portmann B, Eddleston ALWF, Williams $R$. Hepatocellular carcinoma in Great Britain: influence of age, sex, HBsAg status, and aetiology of underlying cirrhosis. Gut 1978; 19: 1022-6.

2 Lygren T. Hepatocellular degeneration (Wilson's disease) and juvenile cirrhosis in the same family. Lancet 1959; 1: 275-6.

3 Vachon A, Paliard P, Grimaud JA, Peyrot-Guillard L, Reiss Th. Les étapes de l'atteinte hépatique de la dégénérescence hépatolenticulaire: lésions précoces, hypertension portale et dégénérescence cancéreuse. A propos de 4 observations. Lyon Med 1973 230: 591-8.

4 Kamakura K, Kimura S, Igarashi S et al. A case of Wilson's disease with hepatoma. J Jap Soc Intern Med 1975; 64: 232-8.
5 Howell JS. The effect of copper acetate on pdimethylaminoazobenzene carcinogenesis in the rat. $\mathrm{Br}$ J Cancer 1958; 2: 594-611.

6 King HJ, Spain JD, Clayton CC. Dietary copper salt and azo dye carcinogenesis. $J$ Nutr 1957; 63: 301-9.

7 Pedero E, Kozelka FL. Effect of copper on hepatic tumors produced by 3 methyl 4 dimethylaminobenzene. AMA Arch Pathol 1951; 52: 455-7.

8 Kamamoto Y, Makiura S, Sugihara S, Hiasa Y, Arai $M$, Ito $N$. The inhibitory effect of copper on DLethionine carcinogenesis in rats. Cancer Res 1973; 33: 1129-35.

9 Sherlock S. Diseases of the liver and biliary system. 6th ed. London: Blackutell Scientific, 1981: 355-64.

10 Walshe JM. The physiology of copper in man and its relation to Wilson's disease. Brain 1967; 90: 149-76.

11 Beresford PA, Gunter JP, Harrison V, Lesna M. Histological demonstration and frequency of intrahepatocytic copper in patients suffering from alcoholic liver disease. Histopathology 1980; 4: 637-43.

12 Krasner N, Johnson PJ, Portmann B, Watkinson G, Macsween RNM, Williams R. Hepatocellular carcinoma in primary biliary cirrhosis: a report of four cases. Gut 1980; 20: 255-8.

13 Wiesner RH, LaRusso NF. Clinicopathologic features of the syndrome of primary sclerosing cholangitis. Gastroenterology 1980; 79: 200-6.

14 Chapman RWG, Arborgh BAM, Rhodes JM et al. Primary sclerosing cholangitis: a review of its clinical featüres, cholangiography, and hepatic histology. Gut 1980; 21: 870-7. 